\title{
ARTICLE
}

Molecular Diagnostics

\section{The prognostic impact of $R A S$ on overall survival following liver resection in early versus late-onset colorectal cancer patients}

Alexandre A. Jácome ${ }^{1}$, Timothy J. Vreeland ${ }^{2}$, Benny Johnson ${ }^{1}$, Yoshikuni Kawaguchi ${ }^{2}$, Steven H. Wei ${ }^{2}$, Y. Nancy You ${ }^{2,3}$, Eduardo Vilar ${ }^{1,4}$, Jean-Nicolas Vauthey ${ }^{2}$ and Cathy Eng (iD)

BACKGROUND: The impact of molecular aberrations on survival after resection of colorectal liver metastases (CLM) in patients with early-age-onset (EOCRC) versus late-age-onset colorectal cancer (LOCRC) is unknown.

METHODS: Patients who underwent liver resection for CLM with known RAS, BRAF and MSI status were retrospectively studied. The prognostic impact of RAS mutations by age was analysed with age as a categorical variable and a continuous variable.

RESULTS: The study included 573 patients, 192 with EOCRC and 381 with LOCRC. The younger the age of onset of CRC, the greater the negative impact on overall survival of RAS mutations in the LOCRC, EOCRC, and $\leq 40$ years (hazard ratio (HR), 1.64 (95\% confidence interval (Cl), 1.23-2.20), 2.03 (95\% Cl, 1.30-3.17), and 2.97 (95\% Cl, 1.44-6.14), respectively. Age-specific mortality risk and linear regression analysis also demonstrated that RAS mutations had a greater impact on survival in EOCRC than in LOCRC (slope: $-4.07,95 \% \mathrm{Cl}-8.10$ to $0.04, P=0.047, R^{2}=0.08$ ).

CONCLUSION: Among patients undergoing CLM resection, RAS mutations have a greater negative influence on survival in patients with EOCRC, more so in patients $\leq 40$ years, than in patients with LOCRC and should be considered as a prognostic factor in multidisciplinary treatment planning.

British Journal of Cancer (2021) 124:797-804; https://doi.org/10.1038/s41416-020-01169-w

\section{BACKGROUND}

Colorectal cancer (CRC) is the third leading cause of cancerrelated death in the US. ${ }^{1}$ Recently, CRC incidence and mortality rates have decreased significantly, likely because of greater utilisation of screening and increased therapeutic options. ${ }^{1-3}$ However, while the overall CRC incidence has declined, the incidence among individuals younger than 55 years has increased by $\sim 2 \%$ per year. ${ }^{4,5}$ The reasons for the increase in CRC incidence in younger individuals are unclear. Lifestyle and environmental factors might explain the increasing incidence of early-age-onset colorectal cancer (EOCRC); obesity has been proposed as a main contributing factor; type 2 diabetes and changes in intestinal microbiome are suspected to be contributing factors. ${ }^{5-10}$

EOCRC exhibits marked molecular genetic heterogeneity, which must be considered in the analysis of risk factors, clinicopathological characteristics, prognostic biomarkers and potential therapeutic targets. The genomic landscapes of EOCRC and late-age-onset CRC (LOCRC) were characterised recently, and while many similarities were noted overall, marked differences were noted in rates of specific mutations when microsatellite stable (MSS) and high-frequency microsatellite instability (MSI-H) subgroups were analysed separately. ${ }^{11}$ Specifically, the most commonly mutated genes in MSS tumours, such as APC, KRAS, BRAF, PIK3CA and AMER1, were less frequent among EOCRC compared to LOCRC. ${ }^{11}$

Patients with EOCRC tend to be treated more aggressively than patients with LOCRC, with no definitive clinical evidence suggesting that EOCRC should be managed distinctly from LOCRC. $^{12-15}$ Studies comparing the prognosis of patients with EOCRC versus LOCRC have shown conflicting results. ${ }^{6}$ Knowledge of the clinical relevance of common mutations according to the age of onset of CRC might be useful to develop distinct treatment strategies and predict the potential impact of personalised therapies in the increasing population of patients with EOCRC.

Hence, we opted to evaluate the prognostic impact of biomarkers starting with the impact of RAS mutations on the overall survival (OS) of patients with EOCRC and LOCRC who underwent curativeintent resection of colorectal liver metastases (CLM).

\footnotetext{
${ }^{1}$ Department of Gastrointestinal Medical Oncology, The University of Texas MD Anderson Cancer Center, Houston, TX, USA; ${ }^{2}$ Department of Surgical Oncology, The University of Texas MD Anderson Cancer Center, Houston, TX, USA; ${ }^{3}$ Clinical Cancer Genetics Program, The University of Texas MD Anderson Cancer Center, Houston, TX, USA and ${ }^{4}$ Department of Clinical Cancer Prevention, The University of Texas MD Anderson Cancer Center, Houston, TX, USA Correspondence: Jean-Nicolas Vauthey (jvauthey@mdanderson.org) or Cathy Eng (cathy.eng@vumc.org)

${ }^{5}$ Present address: Vanderbilt-Ingram Cancer Center, Nashville, TN, USA

These authors contributed equally: Jean-Nicolas Vauthey, Cathy Eng
}

Received: 1 July 2020 Revised: 22 October 2020 Accepted: 28 October 2020

Published online: 19 November 2020 


\section{METHODS}

Study population

Patients who underwent resection of CLM with curative intent at The University of Texas MD Anderson Cancer Center from January 2006 to December 2016 with known RAS, BRAF and MSI status were retrospectively evaluated. Demographic, radiological, surgical, pathological, genetic and medical treatment characteristics were retrieved from electronic medical records. Patients who underwent liver-directed therapy (e.g., radiofrequency ablation, stereotactic radiation therapy) were excluded from the analysis. We followed the Reporting Recommendations for Tumour Marker Prognostic Studies (REMARK) guidelines. ${ }^{16}$ This study was approved by the Institutional Review Board of The University of Texas MD Anderson Cancer Center.

\section{Multidisciplinary management of CLM}

Our institutional approach to surgical management of CLM has been previously detailed. ${ }^{17}$ CLM are deemed resectable when a hepatectomy can achieve a negative margin and preserve more than $30 \%$ of the standardised total liver volume. ${ }^{18}$ Patients with an anticipated insufficient future liver remnant are offered preoperative portal vein embolisation and staged hepatectomy. Patients are typically offered perioperative chemotherapy for a total of 12 cycles. ${ }^{19}$ After resection, patients are followed by either medical or surgical oncology with a history, physical examination, CEA and diagnostic imaging (CT chest, pelvis and abdomen with the liver protocol $(2.5 \mathrm{~mm})$ or an abdominal MRI) every 4 months for the first 2 years post liver resection and then every 6 months for the next 3 years. ${ }^{20}$

\section{Definitions}

EOCRC was defined as CRC in patients $<50$ years old, and LOCRC was defined as CRC in patients $\geq 50$ years old on the date of diagnosis. The primary tumour location was determined based on the surgical pathology report or on colonoscopy. Primary tumours located in the ascending colon or transverse colon were classified as right-sided tumours, and primary tumours located in the splenic flexure, descending colon, or rectum were classified as leftsided tumours. The extrahepatic disease was defined as preoperative radiological findings suggestive of metastatic disease outside the liver or intraoperative findings confirming extrahepatic disease. A positive surgical margin was defined as the presence of tumour cells $<1 \mathrm{~mm}$ from the transection line. The primary tumour $\mathrm{T}$ category and $\mathrm{N}$ category were assigned according to the AJCC Cancer Stating Manual, eighth edition. ${ }^{21}$

Somatic gene mutation profiling

$R A S$ and $B R A F^{V 600 E}$ mutational status were obtained from tissues of the primary tumour or metastatic site, and were assessed using PCR-based DNA sequencing analysis ${ }^{22}$ or next-generation sequencing $^{23}$ performed on formalin-fixed, paraffin-embedded samples. Standardised testing for RAS mutational status was completed for exons 2 (codons 12 and 13), 3 (codons 59 and 61) and 4 (codons 117 and 146) of the KRAS, NRAS and HRAS genes, respectively. MSI status was determined using immunohistochemical analysis of formalin-fixed, paraffin-embedded tumour tissue.

\section{Statistical analysis}

Descriptive statistics were used to summarise demographic and clinical data. Categorical variables were compared by chi-square and Fisher's exact test. Continuous variables were compared by $t$ test. Odds ratios (ORs) and 95\% confidence intervals (Cls) were calculated with the use of the Baptista-Pike method and compared by Fisher's exact test. Hazard ratios (HRs) and $95 \%$ Cls were calculated with the use of the Mantel-Haenszel method. Recurrence-free survival (RFS) was defined as the time in months from the date of the first liver resection to the date of radiological examination or medical evaluation (whichever had occurred first) conclusive of disease recurrence, regardless of the site. OS was defined as the time in months from the date of the first liver resection to the date of death from any cause. The patients who did not have documented recurrence or death or were lost to follow-up were censored on the date of the last contact. RFS and OS were estimated by the Kaplan-Meier method, and the survival curves were compared by the log-rank test. Age-specific mortality risk was estimated by dividing the number of patients in each age-at-diagnosis group who had died by the number of people in the same age group who were exposed to that risk (groups 20-29, 30-39, 40-49, 50-59, 60-69, $70-79$ and $\geq 80$ years old).

Prognostic factors were assessed by multivariate analysis using the Cox proportional hazards model, and $P$ values $<0.05$ were considered statistically significant. The backward stepwise elimination method was used in the variable selection in the regression model. Outliers were detected by using the Robust Regression Followed by the Outlier Identification method. ${ }^{24}$ Outliers were also defined as values greater than 1.5 times the interquartile $75 .{ }^{25}$ Linear regression was used to evaluate the association between continuous variables. The normality of the distribution of variables was examined by the Kolmogorov-Smirnov normality test. Analyses were performed by using SPSS 24.0 software (SPSS, Chicago, IL, USA) and GraphPad Prism software version 8.0.0 (GraphPad Software, San Diego, CA, USA).

\section{RESULTS}

Study population

A total of 573 patients were eligible and were included in the study. All patients underwent at least one liver resection, 47 underwent two liver resections, 7 underwent three liver resections and 1 underwent four liver resections, for a total of 635 liver resections. The median age of the entire cohort was 54 years (range: 22-81 years). A total of 192 patients (34\%) had EOCRC, and 381 patients (66\%) had LOCRC. The EOCRC group had a higher proportion of women, left-sided tumours and extrahepatic disease compared to the LOCRC group (Table 1). Only a small minority of patients were determined to have a BRAF mutation or MSI-H tumour $(<3 \%)$. The EOCRC and LOCRC groups did not differ statistically with respect to the frequency of RAS mutations, BRAF mutation and MSI-H tumours. Most patients received perioperative systemic chemotherapy. Preoperative and postoperative adjuvant chemotherapy were administered to 87 and $69 \%$ of the patients, respectively, in both the EOCRC and LOCRC cohorts. Perioperative systemic chemotherapy predominantly consisted of oxaliplatin-based regimens. Bevacizumab was used in preoperative chemotherapy in $61 \%$ of the patients. Of the 437 patients (76\% of the entire cohort) who had pathologic response classification, 224 (51\%) had a pathologic major response $(<50 \%$ viable tumour cells), and $21(5 \%)$ had a pathologic complete response. A positive surgical margin or margins in the liver resection specimen were found in 91 patients (16\%).

\section{Association between RAS mutations and other baseline} characteristics

An association between RAS mutations and sex was observed in the entire cohort and in the EOCRC and LOCRC subgroups (Supplementary Tables 1 and 2). In the entire cohort, RAS mutations were found in 54\% (128/238) of women versus $38 \%$ (127/335) of men (OR: $1.90,95 \% \mathrm{Cl} 1.36-2.65, P<0.001)$. Similarly, an association between RAS mutations and sidedness was observed in the entire cohort and in the EOCRC and LOCRC subgroups. In the entire cohort, RAS mutations were found in $60 \%$ $(87 / 146)$ of patients with right-sided tumours versus $39 \%$ (168/ 427) of patients with left-sided tumours (OR: $2.27,95 \% \mathrm{Cl}$ 1.56-3.30, $P<0.001)$. An association between sex and sidedness was observed only in the LOCRC group, in which women had 
Table 1. Baseline characteristics of the overall population by the timing of onset of colorectal cancer $(n=573)$.

\begin{tabular}{|c|c|c|c|}
\hline Characteristic & $\begin{array}{l}\text { Early-onset } \\
(n=192)\end{array}$ & $\begin{array}{l}\text { Late-onset } \\
(n=381)\end{array}$ & $P$ value \\
\hline $\begin{array}{l}\text { Median age at diagnosis } \\
\text { (range), y }\end{array}$ & $42(22-49)$ & $59(50-81)$ & $<0.001$ \\
\hline \multicolumn{4}{|l|}{ Sex } \\
\hline Male & $99(52)$ & $236(62)$ & \multirow[t]{2}{*}{0.019} \\
\hline Female & $93(48)$ & $145(38)$ & \\
\hline \multicolumn{4}{|l|}{ RAS status } \\
\hline Mutated & $77(40)$ & $178(47)$ & \multirow[t]{2}{*}{0.154} \\
\hline Wild-type & $115(60)$ & $203(53)$ & \\
\hline \multicolumn{4}{|l|}{ BRAF status } \\
\hline Mutated & $5(3)$ & $4(1)$ & \multirow[t]{2}{*}{0.294} \\
\hline Wild-type & $163(97)$ & $293(99)$ & \\
\hline \multicolumn{4}{|l|}{ MSI status } \\
\hline MSS & $150(98)$ & $204(97)$ & \multirow[t]{2}{*}{0.739} \\
\hline MSI-H & $3(2)$ & $6(3)$ & \\
\hline \multicolumn{4}{|l|}{ Tumour location } \\
\hline Ascending colon & $29(15)$ & $93(25)$ & 0.012 \\
\hline Transverse colon & $8(4)$ & $16(4)$ & 0.527 \\
\hline Descending colon & $9(5)$ & $32(8)$ & 0.122 \\
\hline Rectosigmoid & $146(76)$ & $240(63)$ & 0.001 \\
\hline \multicolumn{4}{|l|}{ Sidedness } \\
\hline Right & $37(19)$ & $109(29)$ & \multirow[t]{2}{*}{0.015} \\
\hline Left & $155(81)$ & $272(71)$ & \\
\hline \multicolumn{4}{|l|}{ CEA level $>10 \mathrm{ng} / \mathrm{mL}$} \\
\hline Yes & $40(22)$ & $101(27)$ & \multirow[t]{2}{*}{0.213} \\
\hline No & $143(78)$ & $271(73)$ & \\
\hline \multicolumn{4}{|l|}{ Bilobar disease } \\
\hline Yes & $39(21)$ & $28(26)$ & \multirow[t]{2}{*}{0.389} \\
\hline No & $149(79)$ & $82(75)$ & \\
\hline \multicolumn{4}{|l|}{$\geq 2$ liver lesions } \\
\hline Yes & $92(48)$ & $182(49)$ & \multirow[t]{2}{*}{1} \\
\hline No & $98(52)$ & $193(51)$ & \\
\hline \multicolumn{4}{|l|}{ Pathologic response } \\
\hline$<50 \%$ viable tumour cells & $73(46)$ & $151(54)$ & \multirow[t]{2}{*}{0.135} \\
\hline$\geq 50 \%$ viable tumour cells & $85(54)$ & $128(46)$ & \\
\hline \multicolumn{4}{|l|}{ Pathologic complete response } \\
\hline Yes & $11(7)$ & $10(4)$ & \multirow[t]{2}{*}{0.16} \\
\hline No & $147(93)$ & $269(96)$ & \\
\hline Margin status & & & \\
\hline Positive & $35(18)$ & $56(15)$ & 0.279 \\
\hline Negative & $157(82)$ & $324(85)$ & \\
\hline Extrahepatic disease & & & \\
\hline Yes & $51(27)$ & $52(14)$ & $<0.001$ \\
\hline No & $141(73)$ & $329(86)$ & \\
\hline Preoperative therapy & & & \\
\hline Yes & $167(87)$ & $330(87)$ & 0.895 \\
\hline No & $24(13)$ & $51(13)$ & \\
\hline Preoperative bevacizumab & & & \\
\hline Yes & $126(66)$ & $222(58)$ & 0.102 \\
\hline No & $66(34)$ & $159(42)$ & \\
\hline Postoperative therapy & & & \\
\hline Yes & $125(68)$ & $260(69)$ & 1 \\
\hline No & $58(32)$ & $119(31)$ & \\
\hline $\begin{array}{l}\text { CEA carcinoembryonic an } \\
\text { frequency MSI, MSS micro } \\
\text { Values are presented as N } \\
p<0.05 \text { was considered st }\end{array}$ & $\begin{array}{l}\text { en, MSI micr } \\
\text { ellite stable. } \\
\text { (\%) unless ot } \\
\text { stically signif }\end{array}$ & $\begin{array}{l}\text { ite instability, } \\
\text { se indicated. }\end{array}$ & high- \\
\hline
\end{tabular}

right-sided tumours more frequently than men did (36\% vs. $24 \%$, OR, 1.75, 95\% Cl 1.11-2.76, $P=0.019$ ).

Survival analysis

The median follow-up period after CLM resection was 70.1 months (95\% Cl, 64.5-75.7 months). Median OS was 70.0 months $(95 \% \mathrm{Cl}$ 61.9-78.2 months). A total of 271 deaths were observed (47\%). Of the 470 patients who had the liver-limited disease, $366(78 \%)$ had a recurrence. Median RFS was 11.4 months (95\% Cl, 10.4-12.3 months).

Multivariate analysis showed that four characteristics were associated with worse OS for all patients: RAS mutations, rightsided tumours, extrahepatic disease and lack of postoperative chemotherapy (Table 2). On multivariate analysis, specifically in the EOCRC group, the presence of extrahepatic disease had an impact on OS $(P=0.046)$; but sidedness and the provision of adjuvant chemotherapy had no bearing on outcome for OS (Table 3). In contrast in the LOCRC group, besides extrahepatic disease, sidedness and the use of adjuvant chemotherapy impacted OS (Table 4).

Overall, patients who harboured RAS mutations had a $58 \%$ higher risk of death following liver resection (Table 2). The negative prognostic impact of RAS mutations was greater in the EOCRC group than in the LOCRC group (HR: $1.90,95 \% \mathrm{Cl}$ $1.20-3.02, P=0.006$ versus HR: $1.53,95 \% \mathrm{Cl} 1.13-2.05, P=0.005)$ (Tables 3 and 4; Fig. 1a, b). Also, the negative prognostic impact of $R A S$ mutations was greater in the population of patients with age at onset of CRC $\leq 40$ years $(n=80)$ (HR: $2.97,95 \% \mathrm{Cl} 1.44-6.14, P<$ $0.05)$ than in patients in the entire EOCRC group or the LOCRC group. Furthermore, when we analysed age as a continuous variable by age-specific mortality risk and by linear regression, our data suggested that RAS mutations had a higher impact on OS in the EOCRC group than in the LOCRC group (Fig. 2 and Supplementary Figs. 1 and 2). Analysis by residual plot raised the possibility that this age-dependent association of RAS mutations might be influenced by the presence of outliers (not shown).

Our cohort had a small number of patients in the extremely young and old age groups ( $<35$ years and $>70$ years), which may explain the presence of possible HR outliers. By applying the Robust Regression Followed by Outlier Identification method for the detection of outliers, we identified 10 groups of age with HRs as outliers (ages 26, 31, 32, 36, 39, 45, 69, 70, 72 and 74 years), which included 58 patients (10\% of the population; in these age groups, patients with RAS mutations had a risk of death much higher than the risk of death of the remaining age groups). Similarly, identifying outliers as values greater than 1.5 times the interquartile $75(\mathrm{HR}>7.12)$ produced the same result. Comparison of the characteristics of the 23 patients with RAS mutations in the outlier group with the 232 patients with RAS mutations in the remaining population showed that the outliers had greater rates of extrahepatic disease (26\% versus $20 \%$ ) and lower rates of receipt of adjuvant chemotherapy (56\% versus $66 \%)$ and neoadjuvant chemotherapy (74\% versus $86 \%)$, which are poor prognostic factors. However, the difference between the outliers and the other patients did not reach statistical significance for any of these comparisons. Multivariate analysis for OS of the outliers confirmed that patients with RAS mutations had a higher risk of death (HR: 16.8, 95\% Cl 5.7-48.8, $P<0.001$ ). Age and sidedness were not prognostic factors among the outliers $(P>0.05)$.

A multivariate analysis of the entire cohort after exclusion of the outliers $(n=515)$ demonstrated that RAS mutations remained a prognostic factor (HR: $1.51,95 \% \mathrm{Cl} 1.17-1.95, P=0.002$ ), together with the extrahepatic disease (HR: $1.60,95 \% \mathrm{Cl} 1.18-2.18, P=$ 0.003 ) and carcinoembryonic antigen level $\geq 10 \mathrm{ng} / \mathrm{mL}$ (HR: 1.39 , 95\% Cl 1.04-1.85, $P=0.024$ ).

A multivariate analysis of the EOCRC patients showed that RAS mutations, extrahepatic disease, and $\geq 2$ liver lesions were associated with worse OS (Table 3). Compared with the subgroup 
Table 2. Results of univariate and multivariate analysis of predictors for overall survival (OS) in the overall population ( $n=573)$.

\begin{tabular}{|c|c|c|c|c|c|c|}
\hline & Categories & Median OS $(95 \% \mathrm{Cl}), \mathrm{mo}$ & $\mathrm{HR}(95 \% \mathrm{Cl})$ & $P$ value & $\mathrm{HR}(95 \% \mathrm{Cl})$ & $P$ value \\
\hline & $\geq 50$ y $(n=381)$ & $68.6(59.3-77.8)$ & & & & \\
\hline \multirow[t]{2}{*}{ Sex } & Male $(n=335)$ & $75.5(65.7-85.3 \mathrm{~m})$ & $0.75(0.59-0.95)$ & 0.021 & $0.88(0.66-1.17)$ & 0.393 \\
\hline & Female $(n=238)$ & $58.9(47.4-70.3)$ & & & & \\
\hline & Wild-type $(n=318)$ & $78.4(66.0-90.8)$ & & & & \\
\hline \multirow[t]{2}{*}{ BRAF status } & Mutated $(n=9)$ & $47.2(3.7-90.7)$ & $1.32(0.54-3.21)$ & 0.536 & $2.01(0.60-6.66)$ & 0.252 \\
\hline & Wild-type $(n=456)$ & $72.2(63.4-81.0)$ & & & & \\
\hline \multirow[t]{2}{*}{ MSI status } & MSI-H $(n=9)$ & Not reached & $0.32(0.04-2.30)$ & 0.259 & $0.28(0.03-2.09)$ & 0.218 \\
\hline & MSS $(n=354)$ & $81.4(67.8-95.0)$ & & & & \\
\hline Sidedness & Right $(n=146)$ & $54.2(47.7-60.7)$ & $1.63(1.26-2.12)$ & $<0.001$ & $1.57(1.20-2.05)$ & 0.001 \\
\hline \multirow[t]{2}{*}{$\geq 2$ liver lesions } & Yes $(n=263)$ & $61.1(50.3-71.8)$ & $1.26(0.99-1.60)$ & 0.057 & $0.88(0.58-1.33)$ & 0.565 \\
\hline & No $(n=294)$ & $77.9(69.2-86.6)$ & & & & \\
\hline \multirow[t]{2}{*}{$\mathrm{pCR}$} & Yes $(n=21)$ & $90.2(40.4-139.9)$ & $0.59(0.28-1.27)$ & 0.182 & $0.63(0.28-1.43)$ & 0.278 \\
\hline & No $(n=416)$ & $67.3(57.5-77.2)$ & & & & \\
\hline \multirow[t]{2}{*}{ Margin status } & Positive $(n=91)$ & $66.6(51.3-82.0)$ & $0.89(0.73-1.43)$ & 0.894 & $1.16(0.65-2.04)$ & 0.607 \\
\hline & Negative $(n=481)$ & $70.6(61.4-79.8)$ & & & & \\
\hline \multirow[t]{2}{*}{ Extrahepatic disease } & Yes $(n=103)$ & $46.0(32.5-59.5)$ & $1.62(1.21-2.17)$ & 0.001 & $1.54(1.15-2.07)$ & 0.004 \\
\hline & No $(n=470)$ & $72.2(63.7-80.7)$ & & & & \\
\hline \multirow[t]{2}{*}{ Postoperative therapy } & Yes $(n=385)$ & $77.8(67.6-88.0)$ & $0.66(0.51-0.85)$ & 0.001 & $0.66(0.51-0.85)$ & 0.001 \\
\hline & No $(n=177)$ & $57.1(48.3-65.8)$ & & & & \\
\hline
\end{tabular}

of patients with EOCRC and wild-type RAS, the subgroup with EOCRC and RAS mutations $(n=77)$ had higher proportions of women, right-sided tumours and extrahepatic disease (Supplementary Table 1). A multivariate analysis of the LOCRC patients showed that RAS mutations, right-sided tumours, extrahepatic disease and lack of postoperative chemotherapy were associated with worse OS (Table 4). Since patients with age near 50 years represent a meaningful subgroup, and their tumours might share molecular characteristics, which could compromise the survival analysis, we repeated the univariate and multivariate analyses excluding patients aged 46 to 59 years. The results were similar to those for the entire cohort. Age group ( $\leq 45$ years and $\geq 60$ years) was not associated with OS, whereas RAS mutations were a prognostic factor (HR: $1.96,95 \% \mathrm{Cl} 1.38-2.79, P<0.001$ ).

\section{DISCUSSION}

The findings of our study suggest that the prognostic value of RAS mutations in patients who underwent CLM resection differs according to the age of onset of CRC and has a greater influence on survival in patients with EOCRC, especially if diagnosed $\leq 40$ years of age.

Our analysis has several positive aspects. The retrospective design of our single-institution study provides a large and homogeneous population of CRC patients who were uniformly deemed to have surgically resectable CLM disease (100\% of the patients had colorectal cancer with liver metastases who underwent surgical resection for curative intent) which allows us to review the role of these biomarkers on the prognosis of both EOCRC and LOCRC. Patients who underwent liver-directed therapy were excluded from this analysis to further support the homogeneity of the patient population. There was the uniformity of the use of neoadjuvant and adjuvant chemotherapy in both groups. Anti-VEGF therapy was the only biologic provided in the neoadjuvant setting. Furthermore, practice patterns at our institution reserved anti-EGFR therapy for the refractory setting especially given the concerning findings of worse PFS when utilised in the neoadjuvant setting. ${ }^{26}$ The long-term median follow-up of 70.1 months also demonstrates adequate follow-up followed by the uniformity of surveillance for all resected patients.

Our study does have its limitations. This is a single-institution, retrospective analysis. The median age of our patient population was younger than the average age of patient in the US impacted by colorectal cancer and is a reflection of the young patient population that is commonly referred to as academic institutions. The primary molecular markers evaluated in this analysis were limited to RAS, BRAF and MSI because these were accepted molecular markers of interest at that time based on published or recently presented data. ${ }^{27-29}$ Our single-institution study was not powered to differentiate the impact of rare, poor prognostic, specific RAS mutations (e.g., NRAS). Cercek et al. previously reported patients with the NRAS MT were less likely to proceed 


\begin{tabular}{|c|c|c|c|c|c|c|}
\hline Characteristic & Categories & Median OS $(95 \% \mathrm{Cl}), \mathrm{mo}$ & $\mathrm{HR}(95 \% \mathrm{Cl})$ & $P$ value & $\mathrm{HR}(95 \% \mathrm{Cl})$ & $P$ value \\
\hline \multirow[t]{2}{*}{ Sex } & Male $(n=99)$ & $70.8(48.8-92.8)$ & $0.82(0.53-1.27)$ & 0.384 & $1.08(0.60-1.94)$ & 0.782 \\
\hline & Female $(n=93)$ & $71.2(48.8-92.8)$ & & & & \\
\hline RAS status & Mutated $(n=77)$ & $53.3(44.5-62.1)$ & $2.03(1.30-3.17)$ & 0.002 & $1.90(1.20-3.02)$ & 0.006 \\
\hline BRAF status & Wild-type $(n=163)$ & $68.4(53.7-83.2)$ & & & & \\
\hline \multirow[t]{2}{*}{ MSI status } & MSI-H $(n=3)$ & Not reached & $0.04(0.0-82.8)$ & 0.424 & $0.0(0.0-\infty)$ & 0.969 \\
\hline & MSS $(n=150)$ & $72.0(53.3-90.8)$ & & & & \\
\hline \multirow[t]{2}{*}{ Sidedness } & Right $(n=37)$ & $47.8(24.8-70.8)$ & $1.84(1.11-3.02)$ & 0.016 & $1.71(0.99-2.94)$ & 0.050 \\
\hline & Left $(n=155)$ & $81.7(58.5-105.0)$ & & & & \\
\hline CEA level > $10 \mathrm{ng} / \mathrm{mL}$ & Yes $(n=40)$ & $71.2(41.9-100.5)$ & $1.10(0.65-1.87)$ & 0.698 & $1.23(0.62-2.45)$ & 0.544 \\
\hline \multirow[t]{2}{*}{$\mathrm{pCR}$} & Yes $(n=11)$ & $90.2(0.0-\infty)$ & $0.63(0.19-2.01)$ & 0.438 & $0.57(0.13-2.41)$ & 0.446 \\
\hline & No $(n=147)$ & $70.8(54.8-86.8)$ & & & & \\
\hline \multirow[t]{2}{*}{ Margin status } & Positive $(n=35)$ & $72.2(0.0-\infty)$ & $0.85(0.48-1.52)$ & 0.597 & $1.06(0.53-2.12)$ & 0.856 \\
\hline & Negative $(n=157)$ & $68.4(51.8-85.1)$ & & & & \\
\hline \multirow[t]{2}{*}{ Extrahepatic disease } & Yes $(n=51)$ & $53.3(33.1-73.5)$ & $1.76(1.11-2.80)$ & 0.015 & $1.64(1.00-2.66)$ & 0.046 \\
\hline & No $(n=141)$ & $72.2(60.2-84.2)$ & & & & \\
\hline \multirow[t]{2}{*}{ Postoperative therapy } & Yes $(n=125)$ & $72.2(44.0-100.4)$ & $0.71(0.44-1.12)$ & 0.144 & $0.64(0.40-1.02)$ & 0.064 \\
\hline & No $(n=58)$ & $59.5(43.8-75.1)$ & & & & \\
\hline
\end{tabular}

\begin{tabular}{|c|c|c|c|c|c|c|}
\hline Characteristic & Categories & Median OS $(95 \% \mathrm{Cl})$, mo & $\mathrm{HR}(95 \% \mathrm{Cl})$ & $P$ value & HR $(95 \% \mathrm{Cl})$ & $P$ value \\
\hline \multirow[t]{2}{*}{ Sex } & Male $(n=236)$ & $75.5(64.2-86.8)$ & $0.70(0.52-0.94)$ & 0.019 & $0.90(0.63-1.30)$ & 0.591 \\
\hline & Female $(n=145)$ & $56.8(43.2-70.4)$ & & & & \\
\hline RAS status & Mutated $(n=178)$ & $52.2(39.0-65.4)$ & $1.64(1.23-2.20)$ & 0.001 & $1.53(1.13-2.05)$ & 0.005 \\
\hline BRAF status & Wild-type $(n=293)$ & $78.2(68.3-88.1)$ & & & & \\
\hline \multirow[t]{2}{*}{ MSI status } & MSI-H $(n=6)$ & Not reached & $0.59(0.08-4.26)$ & 0.603 & $1.12(0.12-9.74)$ & 0.916 \\
\hline & MSS $(n=204)$ & $83.2(69.2-97.3)$ & & & & \\
\hline \multirow[t]{2}{*}{ Sidedness } & Right $(n=109)$ & $54.3(47.1-61.6)$ & $1.56(1.15-2.12)$ & 0.004 & $1.53(1.12-2.09)$ & 0.007 \\
\hline & Left $(n=272)$ & $76.3(64.5-88.1)$ & & & & \\
\hline \multirow[t]{2}{*}{$\mathrm{pCR}$} & Yes $(n=10)$ & $93.6(0.0-\infty)$ & $0.58(0.21-1.58)$ & 0.291 & $0.80(0.25-2.58)$ & 0.713 \\
\hline & No $(n=269)$ & $64.9(51.7-78.1)$ & & & & \\
\hline \multirow[t]{2}{*}{ Margin } & Positive $(n=56)$ & $62.6(47.7-77.5)$ & $1.15(0.75-1.74)$ & 0.509 & $1.02(0.56-1.86)$ & 0.944 \\
\hline & Negative $(n=324)$ & $72.1(61.9-82.3)$ & & & & \\
\hline \multirow[t]{2}{*}{ Extrahepatic disease } & Yes $(n=52)$ & $45.1(33.3-56.9)$ & $1.57(1.07-2.32)$ & 0.021 & $1.52(1.03-2.25)$ & 0.033 \\
\hline & No $(n=329)$ & $72.1(62.3-82.0)$ & & & & \\
\hline \multirow[t]{2}{*}{ Postoperative therapy } & Yes $(n=260)$ & $78.2(66.7-89.7)$ & $0.64(0.47-0.86)$ & 0.004 & $0.66(0.48-0.89)$ & 0.008 \\
\hline & No $(n=119)$ & $56.8(46.1-67.5)$ & & & & \\
\hline
\end{tabular}



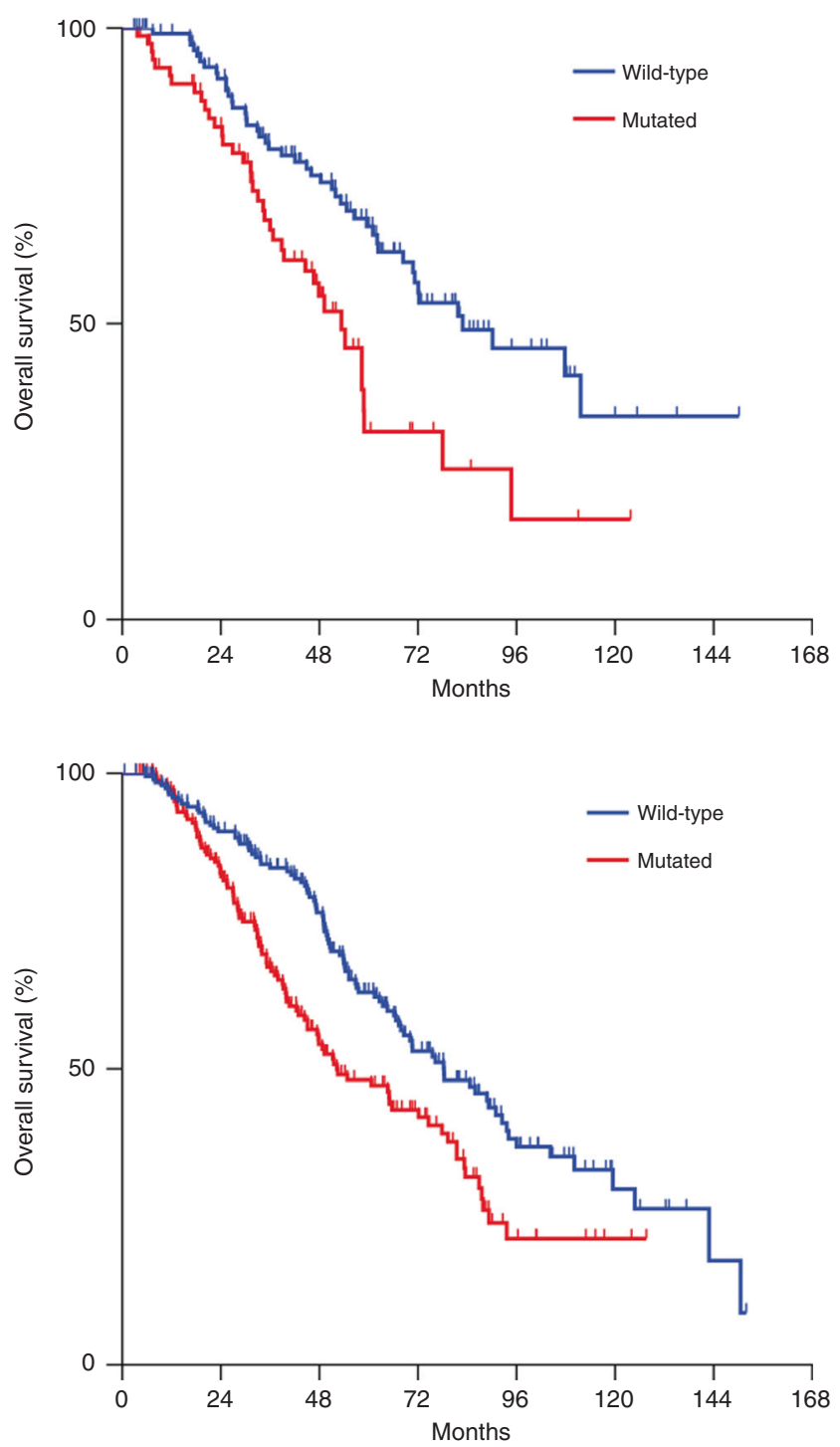

Fig. 1 Overall survival by RAS mutation status. Overall survival by RAS mutation status in patients with (a) early-age-onset $(n=192)$ and (b) late-age-onset $(n=381)$ colorectal cancer.

with surgical resection and had reduced OS relative to KRAS MT patients. $^{30}$

Our findings may be influenced by a subgroup of patients with RAS mutations who had a higher risk of death than patients with $R A S$ mutations in the remaining population. These outliers were identified by two concordant methods. These patients accounted for $10 \%$ of the patients in the entire cohort and had increased rates of poor prognostic factors in addition to RAS mutations. This raises the hypothesis that there is a subgroup of patients with RAS mutations who have an extremely high risk of death after CLM resection. The absence of statistically significant differences in the rates of poor prognostic factors between the outliers with RAS mutations and the patients with RAS mutations in the remaining population was probably due to the small sample size of outliers. The lower frequency of patients in the extremely young and old age groups might explain the presence of the outliers. However, a definitive explanation would only be possible with an analysis of a much larger population of patients in those age groups ( $<35$ years and $>70$ years).
Since the use of postoperative therapy was not mandatory and it was a significant predictor for OS on the overall population on multivariate analysis, imbalances in the rates of postoperative therapy among subgroups could influence our findings. However, there was no difference in the use of postoperative therapy by age and by RAS status (Supplementary Tables 1 and 2).

Our findings regarding the prognostic value of RAS mutations in patients with EOCRC are concordant with previous reports of lower tumour mutational burden in this patient group. Tumour mutational burden increases significantly with age and maybe up to 2.4 times as high in someone diagnosed with cancer at 90 years of age as it is in someone diagnosed with cancer at 10 years of age. ${ }^{31}$ We were able to find no similar studies examining other RAS-driven malignancies, such as pancreatic cancer and non-small cell lung cancer (NSCLC), possibly because few young patients experience these cancers. However, a study in a cohort of NSCLC patients demonstrated that patients younger than 50 years had a higher probability of harbouring a targetable genotype. ${ }^{32}$ This suggests that age might be an underappreciated marker for specific mutational profiles. Interestingly, we found no such association of age with BRAF mutation or MSI-H. This is most likely because our cohort had very low rates of these two molecular abnormalities.

The development of tailored therapies for RAS-driven malignancies has been elusive. A recently presented Phase 1 trial showed encouraging results of targeted therapies for the specific $K R A S^{G 12 C}$ mutation. ${ }^{33}$ The study evaluated the efficacy and safety of a $R A S^{G 12 C}$ inhibitor (AMG 510) in patients who had locally advanced or metastatic solid tumours and harboured $R A S^{G 12 C}$ mutation. Of ten patients with NSCLC, five patients showed a partial response, and four had stable disease. These findings had a minimal benefit in the colorectal cohort. ${ }^{34,35}$

Our study suggests that RAS mutations have a significantly greater impact on survival after CLM resection in patients with EOCRC than in patients with LOCRC. In addition, in the presence of extrahepatic disease, consideration of liver resection in an EOCRC patient should be considered with caution. With nextgeneration sequencing (NGS) now as a standard of care, it is likely additional molecular markers will be identified in the EOCRC versus LOCRC patient population that may be prognostic and possibly predictive for OS following CLM resections. Inclusion of adjunct tools, such as immunoscore, ${ }^{36}$ a robust and validated test of the host immune reaction measuring CD3+ and CD8 + T-cell densities within the tumour and/or detection of ctDNA may be considered for determination of the risk of recurrence. $^{37,38}$ To our knowledge, this is the first study determining the influence of RAS mutations on overall survival from the perspective of the age of onset in RAS-driven colorectal cancer liver resections.

\section{ACKNOWLEDGEMENTS}

The authors thank all the patients that underwent hepatic resection at MD Anderson; Ms. Ruth Haynes for administrative support; Ms. Stephanie Deming, an employee of the Research Medical Library at MD Anderson Cancer Center and Ms. Jennifer Whisenant for copyediting the paper.

\section{AUTHOR CONTRIBUTIONS}

A.A.J. worked in conception, data collection, data analysis, statistical analysis, paper writing and paper review. T.V. in data collection, data analysis, statistical analysis, paper writing and paper review. B.J. in data analysis, paper writing and paper review. Y.K. in data collection, data analysis and paper review. S.H.W. in data collection, data analysis and paper review. Y.Q.N.Y. in data analysis and paper review. E.V. in data analysis and paper review. J.N.V. in conception, data collection, data analysis, paper writing and paper review. C.E. in conception, data analysis, statistical analysis, paper writing and paper review. 




Fig. 2 Age-specific mortality risk by RAS status. Age-specific mortality risk was estimated by dividing the number of patients in each age-atdiagnosis group who had died by the number of people in the same age group who were exposed to that risk (groups 20-29, 30-39, 40-49, $50-59,60-69,70-79$ and $\geq 80$ years of age). The area between the curves is the sum of the hazard ratios of death; the larger the area, the stronger the age-specific prognostic value of RAS mutations. RAS mutations had a stronger prognostic value in early-onset CRC. The fact that the curves are closer around 50 years suggests that the risk is similar in patients diagnosed with CRC in middle age.

\section{ADDITIONAL INFORMATION}

Ethics approval and consent to participate This study was approved by the Institutional Review Board (IRB) of The University of Texas MD Anderson Cancer Center. The informed consent was waived by the IRB. The study was performed in accordance with the Declaration of Helsinki.

Consent to publish Not applicable.

Data availability The datasets of the study contain personal health information and are confidential. These are available to readers upon reasonable request.

Competing interests The authors declare no competing interest.

Funding information This research was supported in part by the National Institutes of Health through MD Anderson's Cancer Center Support Grant, CA016672, which supports the Clinical Trials Office.

Supplementary information is available for this paper at https://doi.org/10.1038/ s41416-020-01169-w.

Publisher's note Springer Nature remains neutral with regard to jurisdictional claims in published maps and institutional affiliations.

\section{REFERENCES}

1. Siegel, R. L., Miller, K. D. \& Jemal, A. Cancer statistics, 2019. CA Cancer J. Clin. 69 7-34 (2019).

2. Cress, R. D., Morris, C., Ellison, G. L. \& Goodman, M. T. Secular changes in colorectal cancer incidence by subsite, stage at diagnosis, and race/ethnicity, 1992-2001. Cancer 107, 1142-1152 (2006).

3. Siegel, R. L., Ward, E. M. \& Jemal, A. Trends in colorectal cancer incidence rates in the United States by tumor location and stage, 1992-2008. Cancer Epidemiol. Biomark. Prev. 21, 411-416 (2012).

4. You, Y. N., Xing, Y., Feig, B. W., Chang, G. J. \& Cormier, J. N. Young-onset colorectal cancer: is it time to pay attention? Arch. Intern Med 172, 287-289 (2012).

5. Murphy, C. C., Singal, A. G., Baron, J. A. \& Sandler, R. S. Decrease in incidence of young-onset colorectal cancer before recent increase. Gastroenterology 155, 1716-1719 (2018).

6. Mauri, G., Sartore-Bianchi, A., Russo, A. G., Marsoni, S., Bardelli, A. \& Siena, S. Earlyonset colorectal cancer in young individuals. Mol. Oncol. 13, 109-131 (2019).
7. Aleksandrova, K., Pischon, T., Buijsse, B., May, A. M., Peeters, P. H., Bueno-deMesquita, H. B. et al. Adult weight change and risk of colorectal cancer in the European Prospective Investigation into Cancer and Nutrition. Eur. J. Cancer 49, 3526-3536 (2013).

8. Bailey, C. E., Hu, C.-Y., You, Y. N., Bednarski, B. K., Rodriguez-Bigas, M. A., Skibber, J. $M$. et al. Increasing disparities in the age-related incidences of colon and rectal cancers in the United States 1975-2010. JAMA Surg. 150, 17-22 (2015).

9. Bassett, J. K., Severi, G., English, D. R., Baglietto, L., Krishnan, K., Hopper, J. L. et al. Body size, weight change, and risk of colon cancer. Cancer Epidemiol. Biomark. Prev. 19, 2978-2986 (2010).

10. Hedley, A. A., Ogden, C. L., Johnson, C. L., Carroll, M. D., Curtin, L. R. \& Flegal, K. M. Prevalence of overweight and obesity among US children, adolescents, and adults, 1999-2002. J. Am. Med. Assoc. 291, 2847-2850 (2004).

11. Lieu, C. H., Golemis, E. A., Serebriiskii, I. G., Newberg, J. Y., Hemmerich, A., Connelly, C. et al. Comprehensive genomic landscapes in early and later onset colorectal cancer. Clin. Cancer Res. 25, 5852-5858 (2019).

12. Abdelsattar, Z. M., Wong, S. L., Regenbogen, S. E., Jomaa, D. M., Hardiman, K. M. \& Hendren, S. Colorectal cancer outcomes and treatment patterns in patients too young for average-risk screening. Cancer 122, 929-934 (2016).

13. Kneuertz, P. J., Chang, G. J., Hu, C.-Y., Rodriguez-Bigas, M. A., Eng, C., Vilar, E. et al. Overtreatment of young adults with colon cancer: more intense treatments with unmatched survival gains. JAMA Surg. 150, 402-409 (2015).

14. Van Cutsem, E., Cervantes, A., Adam, R., Sobrero, A., Van Krieken, J., Aderka, D. et al. ESMO consensus guidelines for the management of patients with metastatic colorectal cancer. Ann. Oncol. 27, 1386-1422 (2016).

15. Benson, A. B., Venook, A. P., Al-Hawary, M. M., Cederquist, L., Chen, Y.-J., Ciombor, K. K. et al. NCCN guidelines insights: colon cancer, version 2.2018. J. Nat/ Compr. Canc Netw. 16, 359-369 (2018).

16. McShane, L. M., Altman, D. G., Sauerbrei, W., Taube, S. E., Gion, M. \& Clark, G. M. REporting recommendations for tumor MARKer prognostic studies (REMARK). Breast Cancer Res. Treat. 100, 229-235 (2006).

17. Kawaguchi, Y., Kopetz, S., Newhook, T., Mario, D., Chun, Y. S., CW, D. T. et al. Mutation status of RAS, TP53, and SMAD4 is superior to mutation status of RAS alone for predicting prognosis after resection of colorectal liver metastases. Clin. Cancer Res. 25, 5843-5851 (2019).

18. Kishi, Y., Abdalla, E. K., Chun, Y. S., Zorzi, D., Madoff, D. C., Wallace, M. J. et al. Three hundred and one consecutive extended right hepatectomies: evaluation of outcome based on systematic liver volumetry. Ann. Surg. 250, 540-548 (2009).

19. Brouquet, A., Abdalla, E. K., Kopetz, S., Garrett, C. R., Overman, M. J., Eng, C. et al. High survival rate after two-stage resection of advanced colorectal liver metastases: response-based selection and complete resection define outcome. J. Clin. Oncol. 29, 1083-1090 (2011).

20. Kawaguchi, Y., Lillemoe, H. A., Panettieri, E., Chun, Y. S., Tzeng, C. W. D., Aloia, T. A. et al. Conditional recurrence-free survival after resection of colorectal liver 
The prognostic impact of RAS on overall survival following liver... AA Jácome et al.

metastases: persistent deleterious association with RAS and TP53 Co-mutation. J. Am. Coll. Surg. 229, 286-294 (2019).

21. Amin, M. B., Greene, F. L., Edge, S. B., Compton, C. C., Gershenwald, J. E., Brookland, R. K. et al. The eighth edition AJCC cancer staging manual: continuing to build a bridge from a population-based to a more "personalized" approach to cancer staging. CA Cancer J. Clin. 67, 93-99 (2017).

22. Ogino, S., Kawasaki, T., Brahmandam, M., Yan, L., Cantor, M., Namgyal, C. et al. Sensitive sequencing method for KRAS mutation detection by pyrosequencing. J. Mol. Diagn. 7, 413-421 (2005).

23. Tuononen, K., Mäki-Nevala, S., Sarhadi, V. K., Wirtanen, A., Rönty, M., Salmenkivi, K. et al. Comparison of targeted next-generation sequencing (NGS) and real-time PCR in the detection of EGFR, KRAS, and BRAF mutations on formalin-fixed, paraffin-embedded tumor material of non-small cell lung carcinoma-superiority of NGS. Genes Chromosomes Cancer 52, 503-511 (2013).

24. Motulsky, H. J. \& Brown, R. E. Detecting outliers when fitting data with nonlinear regression-a new method based on robust nonlinear regression and the false discovery rate. BMC Bioinforma. 7, 123 (2006).

25. Kiselev, V. Y., Yiu, A. \& Hemberg, M. scmap: projection of single-cell RNA-seq data across data sets. Nat. Methods 15, 359-362 (2018).

26. Primrose, J., Falk, S., Finch-Jones, M., Valle, J., O'Reilly, D., Siriwardena, A. et al. Systemic chemotherapy with or without cetuximab in patients with resectable colorectal liver metastasis: the new EPOC randomised controlled trial. Lancet Oncol. 15, 601-611 (2014).

27. Douillard, J. Y., Oliner, K. S., Siena, S., Tabernero, J., Burkes, R., Barugel, M. et al. Panitumumab-FOLFOX4 treatment and RAS mutations in colorectal cancer. $N$. Engl. J. Med. 369, 1023-1034 (2013).

28. Le, D. T., Uram, J. N., Wang, H., Bartlett, B. R., Kemberling, H., Eyring, A. D. et al. PD1 blockade in tumors with mismatch-repair deficiency. N. Engl. J. Med 372, 2509-2520 (2015)

29. Hong, D. S., Morris, V. K., El Osta, B., Sorokin, A. V., Janku, F., Fu, S. et al. Phase IB study of vemurafenib in combination with irinotecan and cetuximab in patients with metastatic colorectal cancer with BRAFV600E mutation. Cancer Discov. 6, 1352-1365 (2016).

30. Cercek, A., Braghiroli, M. I., Chou, J. F., Hechtman, J. F., Kemeny, N., Saltz, L. et al. Clinical features and outcomes of patients with colorectal cancers harboring NRAS mutations. Clin. Cancer Res. 23, 4753-4760 (2017).

31. Chalmers, Z. R., Connelly, C. F., Fabrizio, D., Gay, L., Ali, S. M., Ennis, R. et al. Analysis of 100,000 human cancer genomes reveals the landscape of tumor mutational burden. Genome Med. 9, 34 (2017).
32. Sacher, A. G., Dahlberg, S. E., Heng, J., Mach, S., Jänne, P. A. \& Oxnard, G. R. Association between younger age and targetable genomic alterations and prognosis in non-small-cell lung cancer. JAMA Oncol. 2, 313-320 (2016).

33. Hong, D. S., Fakih, M. G., Strickler, J. H., Desai, J., Durm, G. A., Shapiro, G. I. et al. KRASG12C inhibition with sotorasib in advanced solid tumors. N. Engl. J. Med. 383, 1207-1217 (2020).

34. Thierry, A. R., Mouliere, F., El Messaoudi, S., Mollevi, C., Lopez-Crapez, E., Rolet, F. et al. Clinical validation of the detection of KRAS and BRAF mutations from circulating tumor DNA. Nat. Med. 20, 430-435 (2014).

35. Peeters, M., Douillard, J.-Y., Van Cutsem, E., Siena, S., Zhang, K., Williams, R. et al. Mutant KRAS codon 12 and 13 alleles in patients with metastatic colorectal cancer: assessment as prognostic and predictive biomarkers of response to panitumumab. J. Clin. Oncol. 31, 759-765 (2013).

36. Kwak, Y., Koh, J., Kim, D. W., Kang, S. B., Kim, W. H. \& Lee, H. S. Immunoscore encompassing $\mathrm{CD} 3+$ and $\mathrm{CD} 8+\mathrm{T}$ cell densities in distant metastasis is a robust prognostic marker for advanced colorectal cancer. Oncotarget 7, 81778-81790 (2016).

37. Narayan, R. R., Goldman, D. A., Gonen, M., Reichel, J., Huberman, K. H., Raj, S. et al. Peripheral circulating tumor DNA detection predicts poor outcomes after liver resection for metastatic colorectal cancer. Ann. Surg. Oncol. 26, 1824-1832 (2019).

38. Schøler, L. V., Reinert, T., Ørntoft, M. W., Kassentoft, C. G., Árnadóttir, S. S., Vang, S. et al. Clinical implications of monitoring circulating tumor DNA in patients with colorectal cancer. Clin. Cancer Res. 23, 5437-5445 (2017).

(i) Open Access This article is licensed under a Creative Commons Attribution 4.0 International License, which permits use, sharing, adaptation, distribution and reproduction in any medium or format, as long as you give appropriate credit to the original author(s) and the source, provide a link to the Creative Commons license, and indicate if changes were made. The images or other third party material in this article are included in the article's Creative Commons license, unless indicated otherwise in a credit line to the material. If material is not included in the article's Creative Commons license and your intended use is not permitted by statutory regulation or exceeds the permitted use, you will need to obtain permission directly from the copyright holder. To view a copy of this license, visit http://creativecommons. org/licenses/by/4.0/.

(c) The Author(s) 2020 